\title{
Stem cell-derived mitochondria transplantation: a novel strategy and the challenges for the treatment of tissue injury
}

\author{
Jingyu Wang ${ }^{1}$, Heyangzi Li ${ }^{2}$, Ying Yao ${ }^{1}$, Tengfei Zhao ${ }^{3}$, Ying-ying Chen², Yue-liang Shen², Lin-lin Wang ${ }^{2 *}$ (D) \\ and Yongjian Zhu ${ }^{*}$
}

\begin{abstract}
Damage of mitochondria in the initial period of tissue injury aggravates the severity of injury. Restoration of mitochondria dysfunction and mitochondrial-based therapeutics represent a potentially effective therapeutic strategy. Recently, mitochondrial transfer from stem cells has been demonstrated to play a significant role in rescuing injured tissues. The possible mechanisms of mitochondria released from stem cells, the pathways of mitochondria transfer between the donor stem cells and recipient cells, and the internalization of mitochondria into recipient cells are discussed. Moreover, a novel strategy for tissue injury based on the concept of stem cell-derived mitochondrial transplantation is pointed out, and the advantages and challenges are summarized.
\end{abstract}

Keywords: Mitochondria, Transfer, Transplantation, Mesenchymal stem cells, Injury

\section{Background}

Mitochondria as the center of cellular metabolism and production of energy arose from $\alpha$-proteobacterium engulfed by a eukaryotic progenitor, consisting of inner and outer membranes that encapsulate the intermembrane space and matrix compartments [1]. In mammalian cells, mitochondria own their special circular and double-stranded genome, which is evolved from selective mitochondrial ancestor genes [2]. It is theorized that mitochondria in descendants are exclusively transmitted from their maternal individuals [3]. However, mitochondrial transfer between

\footnotetext{
* Correspondence: wanglinlin@zju.edu.cn; neurosurgery@zju.edu.cn ${ }^{2}$ Department of Basic Medicine Sciences, School of Medicine, Zhejiang University, Hangzhou 310058, China

'Department of Neurosurgery, The Second Affiliated Hospital of Zhejiang University School of Medicine, Hangzhou 310009, China

Full list of author information is available at the end of the article
}

mammalian cells has been discovered that challenges the current inheritance of mitochondria and mitochondrial DNA (mtDNA), providing novel thinking for some diseases with mitochondrial damage or defect. The damage of mitochondria frequently occurs in the initial period of tissue injury. Release of accumulated ROS, imbalance of calcium ions, and insufficient supply of energy are responsible for mitochondrial damage, which aggravate cellular apoptosis and death around the injured region [4-8]. However, physiological properties of healthy mitochondria including replication, division, fusion, degradation, movement in the cytoplasm, and intercellular transfer provide the possibility of eliminating and replacing the damaged mitochondria [9, 10]. Previous published data show that injection of isolated viable respiration-competent myocardial mitochondria into the ischemic zone just before reperfusion would reverse postischemic functional deterioration and cellular apoptosis and limit infarct size [11]. Thus, replacement of damaged mitochondria may protect cells against further injury.

Stem cells including mesenchymal stem cells (MSCs), umbilical cord blood stem cells, embryonic stem cells, and induced pluripotent stem cells (IPSCs) with selfreplication capabilities can differentiate into somatic cells varying in shape and function [12, 13]. Transplantation of stem cells recently became a hotspot of research to treat tissue injury. Meanwhile, MSCs originating from the mesoderm are favored in stem cell therapy for four reasons: the ability to maintain viability and regenerative capacity after preservation at $-80{ }^{\circ} \mathrm{C}$; simplicity of isolation and cryopreservation; the ability for rapid replication and high potential of multilineage differentiation; and minimal or even no immunoreactivity [14, 15]. Scientists are interested in the question of whether MSCs can transfer their mitochondria to somatic cells. The first report to reveal stem cells as donor cells of mitochondria is between MSCs and cancer cells with impaired mitochondrial respiratory function [16]. Cancer 
cells could accept healthy mitochondria from healthy cells to increase their invasiveness, tumorigenic potential, and resistance to chemotherapy [17-19]. Thus, inhibiting the process of mitochondrial transfer may play a vital role in cancer therapy.

Recently, numerous studies have shown that mitochondrial transfer from stem cells to injured cells has been considered a potential treatment for tissue injury. However, the specific mechanisms and critical factors remain to be identified. Consequently, in this mini review, based on the summary of the phenomena of mitochondrial transfer between stem cells and various mammalian cells, we present a novel strategy for tissue injury by stem cell-derived mitochondrial transplantation, and the advantages and challenges are summarized.

\section{Mitochondrial transfer in vitro}

Material exchange represents a significant form of intercellular communication that permits not only transfer of small molecules or ions, but also transfer of identified intracellular structures including lysosomes, endosomal vesicles, plasma membrane components, and mitochondria in a unidirectional or bidirectional way [20, 21]. It has been revealed that mitochondrial transfer can restore the dysfunctional mitochondria in recipient cells, reprogram the differentiated cells, and even rescue the injured cells [22-24]. Spees et al. [25] first demonstrated that after coculture of A549 $\rho^{\circ}$ cells (lung adenocarcinoma A549 cell line with defective mtDNA) with MSCs, A549 $\rho^{\circ}$ cells could acquire functional mitochondria from MSCs. Also, the isolated mitochondria from the immortalized, untransformed mammary epithelial MCF$12 \mathrm{~A}$ cells could easily enter malignant breast cancer cell lines such as MCF-7, MDA-MB-231, and NCI/ADR-Res cells rather than entering MSF-12A itself. After mitochondrial transfer, the proliferation of these cell lines would be suppressed in a dose-dependent pattern, and the sensitivity of MCF-7 cells to doxorubicin, abraxane, and carboplatin would be increased [26]. Intriguingly, vascular smooth muscle cells cocultured with MSCs induce upregulation of proliferation of MSCs through mitochondrial transfer [27].

Although it has been indicated that isolated mitochondria transfer to injured cells and replace the damaged or defective mitochondria to rescue function, the release of mitochondria may result in a series of immune responses. The mitochondrial components but not intact mitochondria are recognized as damage-associated molecular patterns (DAMPs), which induce strong proinflammatory reactions in the bloodstream and extracellular medium $[28,29]$. For example, mtDNA released into extracellular space induces Toll-like receptor (TLR) 9-mediated inflammation and NRLP3-inflammasome activation $[30,31]$. Collins et al. [32] injected mtDNA into mice joints, which results in inflammation and arthritis. Although the specific mechanisms remain unclear, adjusting the immune surveillance mechanisms of mtDNA and acquiring intact functional mitochondria may promote exogenous mitochondrial donation for therapeutic purposes.

\section{Mitochondrial transfer in vivo}

Although the phenomenon of mitochondrial transfer in cell culture conditions has been widely observed, it is necessary to confirm whether mitochondrial transfer can occur in in-vivo conditions. Recently, evidence indicated that injured neurons are able to capture functional mitochondria from astrocytes [33]. CD38/CADPR/Ca ${ }^{2+}$ signaling may help astrocytes transfer mitochondria into neurons and promote survival and plasticity. In addition, Hayakawa et al. [34] collected extracellular mitochondria particles from primary mouse cortical astrocytes and then directly injected them into peri-infarct cortex of mouse models of focal cerebral ischemia. After $24 \mathrm{~h}$, results suggested that transplanted functional mitochondria were indeed present in neurons and cell survival signals were amplified. Furthermore, Yi et al. [35] also observed mitochondrial transfer during embryonic development. They collected mitochondria concentrates from murine hepatocytes, and then injected them into zygotes from older mice. There were better developmental outcomes in the injected group than in the control group, which showed that mitochondrial transfer can improve embryonic development. Moreover, replacement of mitochondria through nuclear transfer among oocytes has turned into a research focus recently on the strategy for preventing the inheritance of mtDNA diseases [36].

Stem cells are recognized as unexceptionable donor cells for mitochondrial transfer and numerous studies have substantiated the significance of mitochondrial transfer in stem cell therapy, especially MSCs [37]. The first evidence for mitochondrial transfer as an in-vivo therapeutic tool came from Islam et al.'s study [38]. In the sepsis acute lung injury (ALI) model (airway-instilled E. coli LPS in anesthetized mice), bone marrow mesenchymal stem cells (BMSCs) transferred mitochondria to the alveolar epithelium that increased the generation of ATP and alveolar surfactant that regulates alveolar stability. In such nonsterile inflammatory diseases, alveolar macrophages activated by LPS that are widely used to mimic Gram-negative bacterial infection can accept mitochondria from stem cells to reduce the production of inflammatory factor while increasing the phagocytic ability and the production of ATP [38, 39]. Lung alveolar macrophages had been shown to gain mitochondria from MSCs in both in-vitro and in-vivo models of acute respiratory distress syndrome (ARDS) that result in an 
enhancement of macrophage phagocytosis activity and an improvement of bioenergetics, providing evidence for the therapeutic potential of mitochondria in acute, inflammatory lung disease [40]. In addition, in viral infection, Guo et al. [41] found that the formation of TNTs could be induced via porcine reproductive and respiratory syndrome virus between infected and uninfected cells, and mitochondria derived from stem cells transferred to infected cells depending on TNTs, which rescued infected cells from apoptosis/necrosis, whereas the mitochondria can be a vehicle to transport viral materials for spreading the infection.

In sterile inflammatory diseases induced via contusion, ischemia-reperfusion, or chemical injury, stem cells are capable of alleviating the inflammatory response and rescuing injured cells [42-44]. For instance, Naji et al. [45] indicated that the NLRP3-ASC-Caspase 1 axis induced via indium-tin-oxide nanoparticles in macrophages can provoke pyroptosis, while stem cells can inhibit the inflammatory process. In addition, MSCs rescue cardiomyoblasts from ischemia via direct cell-to-cell connections [46]. Li et al. [47] discovered that the devotion of mitochondria in MSCs provides great promise for the recovery of cigarette smoke (CS)-induced lung injury in chronic obstructive pulmonary disease. Meanwhile, it is reported that there is a higher mitochondrial transfer capacity in iPSC-MSCs than that from BMSCs to repair CS-induced mitochondrial damage. The reduction of the linear intercept value and the improvement in fibrosis were also greater in the group treated with iPSC-MSCs than in those treated with BMSCs [48]. Furthermore, mitochondrial transfer can also occur from MSCs to T cells in systemic lupus erythematosus patients.

Collectively, we summarize the latest studies of mitochondrial transfer via different kinds of stem cells (Table 1). Mitochondria from injured somatic cells are engulfed and degraded by stem cells, which results in induction of the cytoprotective enzyme heme oxygenase-1 (HO-1), and

Table 1 Mitochondrial transfer from different kinds of stem cells

\begin{tabular}{|c|c|c|c|c|c|}
\hline Donor cells & Recipient cells & Defects & Methodologies & Effects & References \\
\hline MSCs & A549 $\rho^{\circ}$ cells & $\begin{array}{l}\text { Lack of functional } \\
\text { mitochondria }\end{array}$ & In vitro: coculture & Rescue aerobic respiration & {$[25]$} \\
\hline $\begin{array}{l}\text { IPSCS } \\
\text { MSCS }\end{array}$ & $\begin{array}{l}\text { Airway epithelial } \\
\text { cells }\end{array}$ & CS induced & $\begin{array}{l}\text { In vitro: coculture } \\
\text { In vivo: intravenous } \\
\text { injection }\end{array}$ & Preservation of ATP levels & {$[48]$} \\
\hline MSCs & T cells & Systemic lupus erythematosus & In vitro: coculture & Regulation of autophagy & {$[50]$} \\
\hline MSCS & CECs & $\begin{array}{l}\text { Rotenone-induced oxidative } \\
\text { stress }\end{array}$ & In vitro: coculture & $\begin{array}{l}\text { Mitochondrial function } \\
\text { rescued }\end{array}$ & {$[68]$} \\
\hline $\begin{array}{l}\text { IPSCS } \\
\text { MSCS }\end{array}$ & Myocardial cells & $\begin{array}{l}\text { Anthracycline-induced } \\
\text { damage }\end{array}$ & In vitro: coculture & Protection of damage & {$[85]$} \\
\hline BMSCs & $\begin{array}{l}\text { Alveolar epithelial } \\
\text { cells }\end{array}$ & $\mathrm{ALI}$ & In vivo: airway instilled & $\begin{array}{l}\text { Mitochondrial function } \\
\text { rescued }\end{array}$ & {$[38]$} \\
\hline BMSCs & $\begin{array}{l}\text { Alveolar } \\
\text { macrophages }\end{array}$ & ARDS & In vitro: coculture & $\begin{array}{l}\text { Improvement of phagocytic } \\
\text { capacity }\end{array}$ & {$[40]$} \\
\hline BMSCs & H9c2 cells & Ischemia-reperfusion & In vitro: coculture & Reduction of apoptosis & {$[87]$} \\
\hline BMSCs & $\begin{array}{l}\text { Nucleus pulposus } \\
\text { cells }\end{array}$ & Degenerative disc diseases & In vitro: coculture & Reduction of apoptosis & {$[88]$} \\
\hline MSCs & Neurons & Ischemia-reperfusion & $\begin{array}{l}\text { In vitro: coculture } \\
\text { In vivo: intravenous } \\
\text { injection }\end{array}$ & $\begin{array}{l}\text { Reduction of brain lesion } \\
\text { volume }\end{array}$ & {$[86]$} \\
\hline MSCs & HUVECS & Ischemia-reperfusion & In vitro: coculture & $\begin{array}{l}\text { Reduction of apoptosis and } \\
\text { rescue of aerobic } \\
\text { respiration }\end{array}$ & \\
\hline BMSCs & Myocardial cells & None & In vitro: coculture & $\begin{array}{l}\text { Reprogramming to the } \\
\text { progenitor state }\end{array}$ & {$[22]$} \\
\hline $\begin{array}{l}\text { Endothelial } \\
\text { progenitor } \\
\text { cells }\end{array}$ & $\mathrm{ECS}$ & Adriamycin induced & $\begin{array}{l}\text { In vivo: tail intravenous } \\
\text { injection }\end{array}$ & $\begin{array}{l}\text { Reduction of inflammation } \\
\text { and apoptosis }\end{array}$ & {$[89]$} \\
\hline MSCs & ECs & Asthma & $\begin{array}{l}\text { In vitro: coculture } \\
\text { In vivo: intravenous } \\
\text { injection }\end{array}$ & $\begin{array}{l}\text { Mitochondrial respiratory } \\
\text { function rescued }\end{array}$ & \\
\hline
\end{tabular}

ALI acute lung injury, ARDS acute respiratory distress syndrome, ATP adenosine triphosphate, BMSC bone marrow mesenchymal stem cell, CS cigarette smoke, EC epithelial cell, HUVEC human umbilical vein endothelial cell, IPSC induced pluripotent stem cell, MSC stem cell including mesenchymal stem cell, CECS cornneal epithelial cells 
improvement of cellular proliferation and antiapoptotic function. Stem cells also donate their mitochondria to injured cells to resist oxidative stress and improve the state of cellular metabolism [49]. Thus, intercellular mitochondrial transfer holds a new approach to cure mitochondrial dysfunctional diseases using stem cells as a carrier [50].

\section{Mechanisms in mitochondrial release from stem cells}

The first step of mitochondrial transfer is the release of mitochondria from donor cells. It has been suggested that mitochondrial Rho-GTPase 1 (Miro1) may be convenient for the release of mitochondrial transfer. Ahmad et al. [51] first suggested that Miro1 as a calcium-sensitive adaptor protein regulates intercellular mitochondrial movement from MSCs to epithelial cells (ECs). The authors developed an in-vitro system of coculture of MSCs and ECs as well as an in-vivo system of mice treated with MSCs via the trachea. The mitochondrial transfer was related to a remarkable recovery of impairment of mitochondrial function. Interestingly, mitochondrial transfer could be blocked when MSCs were preinduced with rotenone, a mitochondrial complex I inhibitor. They then examined the levels of mitochondrial intracellular transport-related proteins and suggested that only Miro1 was associated with the mitochondrial transfer. In addition, MSCs with stronger capacity of mitochondrial transfer than lung ECs and fibroblasts expressed high levels of Miro1 as compared to them. They further showed that, compared to control MSCs, the replacement of mitochondria from MSCs in which Mirol was knocked down to injured ECs was reduced. This decrease was not due to the amount of TNTs, but the mitochondrial motility through the nanotubules. Other research showed that Miro1 protein plays a significant role in $\mathrm{Ca}^{2+}$ uptake into the mitochondria, which subsequently affects mitochondrial movement [52]. In conclusion, Miro1 is an integral protein involved in mitochondrial release from MSCs to ECs and Miro1overexpressing MSCs are efficient mitochondrial donors with enhanced rescue potential.

At present there are three regulations for mitochondrial transport inside cells, which is believed to be involved in mitochondria release. The first is synaptic activity-dependent regulation. Mitochondria are transported to activated synapses in response to two intracellular signals that control their velocity and recruitment into the stationary pool. Identification of the KIF5-Milton-MIRO complex provides molecular targets to address this issue and studies independently identified MIRO as a $\mathrm{Ca}^{2+}$ sensor, providing a potential mechanism underlying $\mathrm{Ca}^{2+}$-dependent regulation of mitochondrial mobility [53-55]. The second regulation is neuronal signaling-mediated regulation. In dorsal root ganglion neurons, nerve growth factor (NGF) can act as a docking signal, causing axonal mitochondria to accumulate close to an external source of NGF [56]. Actin-based mechanisms appear to also have a role in this phenomenon. When neurons are treated with inhibitors of phosphoinositide 3-kinase (PI3K) or latrunculin B, an agent that destabilizes filamentous actin, mitochondria are not recruited to the NGF stimulation site, highlighting a crucial role for the PI3K signaling cascade in NGF-induced regulation of mitochondrial mobility. The third regulation of mitochondrial transport is related to microtubule-associated proteins (MAPs) [57]. Microtubules are dynamic structures and are stabilized by MAPs. Whereas MAP2 is specifically distributed in dendrites, MAP1B and tau are mainly axon-targeted MAPs. In addition to stabilizing axonal microtubules, tau has been shown to contribute to the regulation of the axonal transport of membrane organelles, including mitochondria [58]. Overexpressing tau in N2a and NB2a/d1 neuroblastoma cell lines, primary cortical neurons, and retinal ganglion neurons selectively inhibits kinesin-driven anterograde mitochondrial transport [58-60]. Recent studies have also revealed that the tau-mediated inhibition of axonal mitochondrial transport can be rescued by tau phosphorylation by MARK [61].

Moreover, the specific regulatory mechanisms of stem cell-derived mitochondrial transfer is still not clear. It has been suggested that the CD38/CADPR/Ca ${ }^{2+}$ signaling pathway mediates the mitochondrial transfer from astrocytes into neurons [33]. Thus, it is worth exploring whether this signaling pathway similarly works in stem cells. Are there any other factors and other signal pathways regulating the release of mitochondria? We speculated that the microenvironment of injured regions may send messengers to the stem cells to initiate the transfer of mitochondria. For example, whether molecules such as proinflammatory cytokines (IL-1, TNF- $\alpha$ ) or anti-inflammatory cytokines (IL-4, IL-10), which are released in the early stage of injured tissue, can be recognized by stem cells and result in promoting or inhibiting mitochondrial release. It is interesting to know that dysfunctional mitochondria derived from injured cells can be engulfed and degraded by MSCs, which can result in induction of the cytoprotective enzyme heme oxygenase-1 (HO-1) and stimulation of mitochondrial biogenesis. As a result, stem cells are motivated and recruited, and then release their mitochondria to rescue the injured cells.

\section{Tunneling nanotube-dependent mitochondria internalization mechanism}

Tunneling nanotubes (TNTs) are small membranous tubes with $50-1000 \mathrm{~nm}$ in diameter, which originated from stem cells during mitochondrial transfer. TNTs are thin cytoplasmic extensions bordered by a plasma 
membrane and connecting cells. TNTs were initially described by Rustom et al. [62] as a communicating intercellular transport network formed in coculture of human 293 cells and rat PC12 cells. Later, TNT formation was also reported in immune cells, including $\mathrm{B}, \mathrm{T}$, and NK cells, neutrophils, and monocytes, as well as in neurons, glia, cultured prostate cancer cells, and cardiac myocytes. TNTs seem to be a key point for effective mitochondrial transfer, inhibiting abrogating the transmission of cytoplasmic material such as mitochondria from BMSCs to epithelial cells [24], while inhibiting the process of endocytosis or phagocytosis shows little effect [63]. Onfelt et al. [64] observed that thin filaments involving F-actin and also a thicker subset $(0.7 \mu \mathrm{m})$ containing both $\mathrm{F}$-actin and microtubules participated in the formation of TNTs. Meanwhile, M-sec, a mammalian protein, can induce formation of TNTs that only contain actin filaments, but without microtubules [65]. In addition, exchange of cell particles between injured cells and stem cells was required for the formation of TNTs [66]. It also was observed that filopodial extension and retraction by stem cells draws an extension of TNTs from cardiomyocytes [67]. Also, Cdc42 (a small GTPase) plays a critical role in the TNT extension process [65]. Furthermore, mitochondrial transfer can be induced via mitochondrial damage that releases ROS to activate NF$\mathrm{\kappa B}$ and upregulate TNFoip2, enhancing the formation of TNTs [68].

The formation of TNTs was demonstrated to be controlled by some factors in in-vitro cultures, providing guidance for experimental settings and clues about how it might be regulated in vivo. It was observed that high concentrations of glucose play two-sided roles in the formation of TNTs. On the one hand, high concentrations of glucose diminished mitochondrial motility and inhibited mitochondrial trafficking in neurons via regulating Milton and its O-GlcNAcylation [69]. Moreover, TNT-mediated mitochondrial transfer from MSCs to endothelial cells was enhanced by glucose deprivation [66]. On the other hand, in other cell systems, high concentrations of glucose stimulated the formation of TNTs [70, 71]. In addition, it was reported that other factors including low serum, acidic conditions, $\mathrm{H}_{2} \mathrm{O}_{2}$ stimulation, viral infection, or use of chemotherapeutic agents promoted the formation of TNTs [70-75]. All of these studies revealed that the microenvironment around injured cells might be suited to the formation of TNTs, which is beneficial to the transfer of mitochondria.

\section{Microvesicle-dependent mitochondria internalization mechanism}

Stem cells can also employ microvesicles (MVs) that range from 0.1 to $1 \mu \mathrm{m}$ in diameter to transport their mitochondria to other cells. It has been reported that fitting mitochondria from MSCs were taken by arrestin domain-containing protein 1-mediated microvesicles that eventually were engulfed by macrophages [76]. At first, MSC-derived mitochondria in the cytoplasm were packaged into Autophagy Marker Light Chain 3-containing vesicles that then migrated to the cell periphery and were integrated into outward budding blebs in the plasma membrane. This MV-dependent mitochondria transfer was also reported between astrocytes and neurons [34].

\section{Gap junction-dependent mitochondria internalization mechanism}

Live optical studies revealed that BMSCs formed Connexin43 (Cx43)-containing gap junctional channels with the alveolar epithelium, releasing mitochondria-containing microvesicles that were engulfed by the epithelium. In the sepsis ALI model, the distribution of $\mathrm{Cx} 43$ was uneven spatially in the alveolar epithelium, and BMSCs preferred to attach to the areas of high Cx43 expression. In addition, it was demonstrated that $\mathrm{Cx} 43$ was the critical connexin in the present gap junctional channel formation. Furthermore, BMSCs loaded with $\mathrm{Ca}^{2+}$ chelator successfully attached to the alveolar but failed to form nanotubes and microvesicles, which suggested that the $\mathrm{Ca}^{2+}$ was gap junctional channel dependent [38]. Subsequently, Cx43-based intercellular gap junctional communication also occurred in coculture of MSCs and endothelial cells [77]. These findings supported Cx43-dependent mechanisms and transfer of viable mitochondria in the protective response.

\section{Macropinocytosis-dependent mitochondria internalization mechanism}

Macropinocytosis was suggested recently to play a role in mitochondrial internalization into cardiomyocytes [78, 79]. Ethyl isopropyl amiloride (EIPA) can abolish the therapeutic effect of mitochondrial transfer in h9c2 cardiomyoblasts as specific inhibitors of micropinocytosis [78]. To further assess the contribution of macropinocytosis in mitochondrial transfer, the inhibitory effects of other macropinocytosis and endocytosis inhibitors were measured by FACS after coincubation of EMCs with isolated DsRed2-labeled mitochondria. Mitochondrial transfer was reduced by cytochalasin D (inhibitor of actin polymerization) and nocodazole (inhibitor of microtubule assembly) but not by chlorpromazine (inhibitor of clathrin-mediated endocytosis), revealing that cells acquired exogenous mitochondria via micropinocytosis (not via clathrin-mediated endocytosis) [79]. In addition, integrity of the mitochondria outer membrane proteins and interaction with cellular heparan sulfate proteoglycan are essential for cells acquiring exogenous mitochondria. 
Actin-dependent mitochondria internalization mechanism Studies have shown that internalization of mitochondria occurs through actin-dependent endocytosis and rescues cell function by increasing the ATP content and oxygen consumption rates. Some studies showed that mitochondrial internalization was not conducted by TNTs, caveola/ clathrin-dependent endocytosis, and macropinocytosis. Only preincubation with cytochalasin D which has been well recognized to inhibit actin-dependent endocytosis and phagocytosis significantly decreased the internalization of mitochondria into cardiomyocytes and decreased the ATP content [80].

The mechanisms of mitochondrial transfer are summarized in Fig. 1: Recipient cells passively phagocytose microvesicles containing mitochondria released by stem cells; tunneling nanotubes (TNTs), microtubules, or gap junctions occur between stem cells and donor cells for active replacement of intact functional mitochondria.

\section{Strategy and the challenges of stem cell-derived mitochondrial transplantation}

Stem cells have been extensively demonstrated to rescue cell injury, with the specific mechanisms are summarized in Fig. 2. The mechanisms of stem cell therapy include the following aspects: differentiation into injured cells; sequester toxic compounds; paracrine activity for trophic support or anti-inflammatory effects; mitochondrial transfer by TNTs; and transfer of molecules via microvesicles [13, 81, 82]. Meanwhile, mitochondrial transfer between stem cells and injured cells becomes a novel mechanism, both for endogenous and exogenous stem cells. This raised the possibility to transplant stem cellderived mitochondria to injured tissue as a novel strategy for stem cell-based therapy.

Stem cell-derived mitochondrial transplantation may have two main advantages. First, compared with MSCs, mitochondria possess the characteristic of lower immunogenicity because they lack the surface antigens on the surface membrane of MSCs. Thus, we raised the forward hypothesis that the injured recipient may accept stem cell-derived mitochondria from different individuals or even different species because of low immunogenicity. Second, stem cells have the ability for long-time proliferation and amplification, and can amplify to achieve the quantity of mitochondria which is required in clinical therapy.

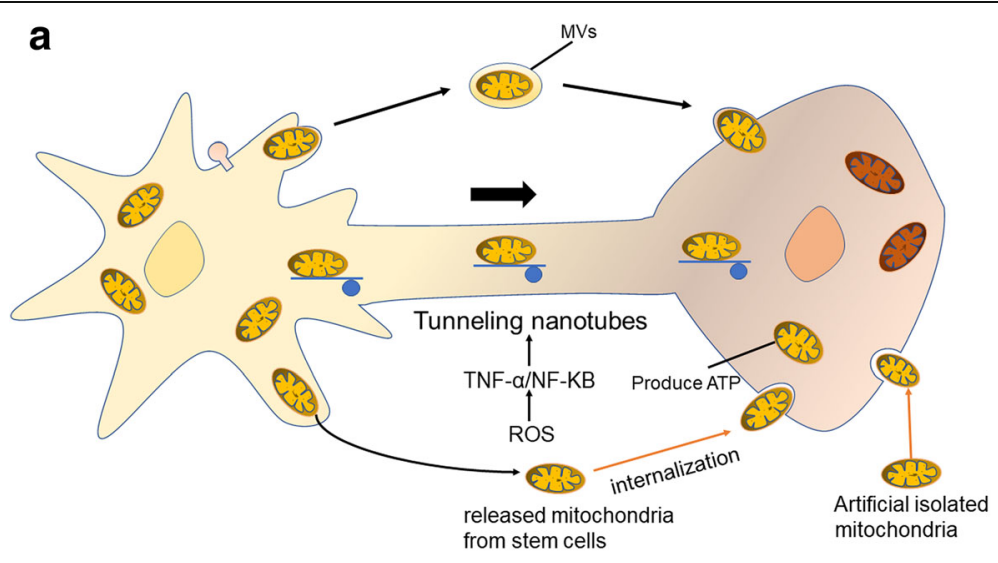

b

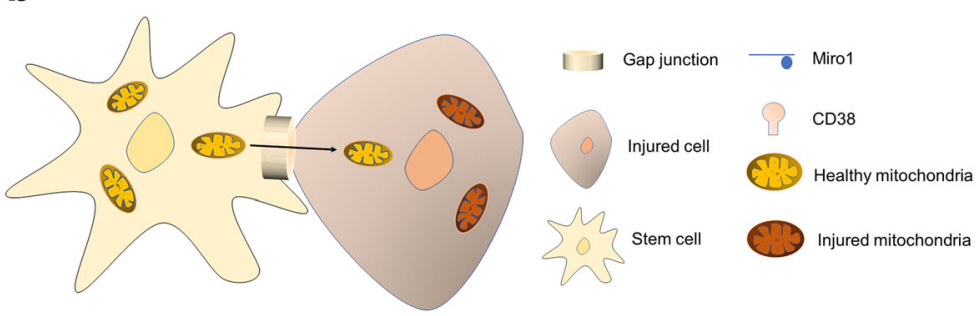

Fig. 1 Mechanisms of mitochondrial transfer. a Formation of TNTs. Cells move apart and form TNTs with each other. Mitochondria can be transported in

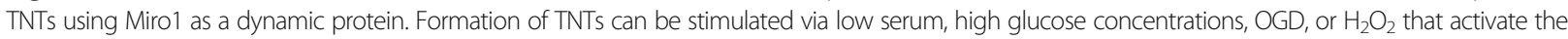
ROS/TNF-a/NF-KB/TNFalp2 pathway. Microvesicles (MVs) ranging from 0.1 to $1 \mu \mathrm{m}$ containing mitochondria can be released from stem cells and engulfed by recipient cells. Mitochondria without MVs released from stem cells can be engulfed by recipient cells through micropinocytosis. Artificial isolated mitochondria can be engulfed by recipient cells through actin-dependent mitochondria internalization. b Gap junction-mediated mitochondrial transfer. Cells containing Cx43 proteins initially closely contact with target cells, followed by formation of gap junction. ATP adenosine triphosphate, Miro1 mitochondrial Rho-GTPase 1, NF nuclear factor, ROS reactive oxygen species, TNF tumor necrosis factor 


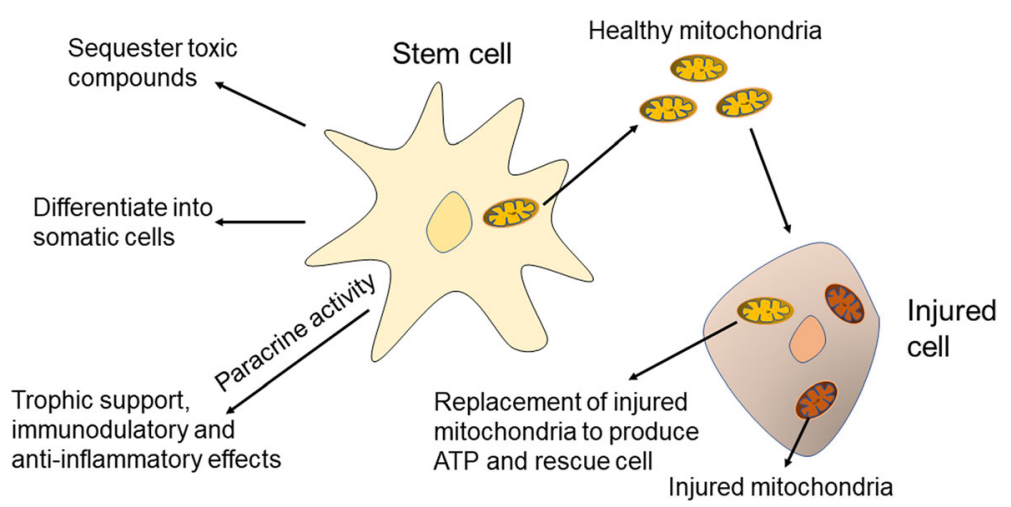

Fig. 2 Mechanism of stem cell therapy. Stem cells became potential therapy for cell injury via various kinds of mechanisms. After cell injury, stem cells proliferate and migrate to damaged areas and then differentiate into degenerated somatic cells. Besides that, stem cells inhibit inflammatory effects that further damage nearby cells and remove toxic compounds accumulated via injured cells. In addition, growth factors that support cellular growth are released by stem cells. Importantly, healthy mitochondria derived from stem cells can transfer into injured cells to replace damaged mitochondria via TNTs or endocytosis. ATP adenosine triphosphate

However, there are many challenges for the use of stem cell-derived mitochondria for clinical treatment. For example, there are multiple technical questions to be resolved. First, how to isolate intact and viable mitochondria from stem cells? Although the intact functional mitochondria can replace the damaged or defective mitochondria to rescue cell function, mitochondrial DNA (mtDNA), but not intact mitochondria, results in a series of immune responses. Thus, to adjust the isolation technique to acquire high-quality active intact mitochondria may promote exogenous mitochondrial donation for therapeutic purposes. Second, how to keep the activity of mitochondria in vitro? Are cryopreserved mitochondria as effective as fresh isolated mitochondria? Third, how to meet the requirement of a sufficient quantity of mitochondria? Fourth, which approach of mitochondria transplantation into individuals should be selected from intravenous or local injection? Fifth, the development of specific fluorescence and mitochondrial tracking tools is required for further detecting the occurrence of mitochondrial transfer in vivo. Recently, there was inspirational discovery of a new tool called MitoCeption to track the transplanted mitochondria, providing a facility for research or application [83]. In addition, using transgenic mitochondrial labeling such as tGFP may be a viable option for tracking transplanted mitochondria both in vitro and in vivo, since the inner mitochondrial membrane can be labeled with high transfection efficiency and expression stability [84]. Finally, the consequence and security of mitochondrial transfer from different kinds of stem cells need to be further explored and evaluated.

\section{Conclusion}

Mitochondrial dysfunction plays a vital role in tissue injury, revealing that restoring the function of mitochondria or replacement of damaged mitochondrial may improve cellular survival after injury. The reasonable application of mitochondrial transfer in mesenchymal stem cell-based therapy for sterile diseases such as myocardial ischemia-reperfusion injury, stroke, neuronal traumatic injury, or chemical nanoparticle-induced lung injury and for acute or chronic inflammatory diseases, such as ALI, will attract more attention in future $[38,48,85,86]$. In these conditions, damaged cells are capable of capturing healthy mitochondria from stem cells to produce ATP, alleviate the inflammatory response, reduce apoptosis, and eventually rescue the injured cells $[67,86,87]$. We believe that this novel strategy for tissue injury based on the concept of stem cell-derived mitochondrial transplantation will be implemented soon in the near future if technical problems are resolved.

\section{Abbreviations}

ARDS: Acute respiratory distress syndrome; CS: Cigarette smoke; EC: Epithelial cell; HO-1: Heme oxygenase-1; IPSC: Induced pluripotent stem cell; MAP: Microtubuleassociated protein; Miro1: Mitochondrial Rho-GTPase 1; MSC: Stem cell including mesenchymal stem cell; mtDNA: Mitochondrial DNA; MV: Microvesicle; NGF: Nerve growth factor; PI3K: Phosphoinositide 3-kinase; TLR: Toll-like receptor;

TNT: Tunneling nanotube

\section{Acknowledgements}

Not applicable.

\section{Funding}

This work was supported by the National Natural Science Foundation of China (No. 81572229, 81673777, and 81401011) and the Natural Science Foundation of Zhejiang, China (No. LY15H060004).

\section{Availability of data and materials Not applicable.}

\section{Authors' contributions}

L-IW and YjZ are responsible for the concept of the review. JyW, HyzL, YY, and TfZ are responsible for writing the first draft of the manuscript. $Y$-yC and Y-IS were responsible for critical review of the manuscript. All authors read and approved the final manuscript.

Ethics approval and consent to participate Not applicable. 


\section{Consent for publication}

Not applicable.

\section{Competing interests}

The authors declare that they have no competing interests.

\section{Publisher's Note}

Springer Nature remains neutral with regard to jurisdictional claims in published maps and institutional affiliations.

\begin{abstract}
Author details
${ }^{1}$ Department of Neurosurgery, The Second Affiliated Hospital of Zhejiang University School of Medicine, Hangzhou 310009, China. ${ }^{2}$ Department of Basic Medicine Sciences, School of Medicine, Zhejiang University, Hangzhou 310058, China. ${ }^{3}$ Department of Orthopedic Surgery, the Second Affiliated Hospital, School of Medicine, Zhejiang University, Hangzhou 310009, China.
\end{abstract}

\section{Published online: 13 April 2018}

\section{References}

1. Lane N, Martin W. The energetics of genome complexity. Nature. 2010; 467(7318):929-34. https://doi.org/10.1038/nature09486

2. Gustafsson CM, Falkenberg M, Larsson NG. Maintenance and expression of mammalian mitochondrial DNA. Annu Rev Biochem. 2016;85(1):133-60. https://doi.org/10.1146/annurev-biochem-060815-014402

3. Stewart JB, Larsson NG. Keeping mtDNA in shape between generations. PLoS Genet. 2014;10(10):e1004670. https://doi.org/10.1371/journal.pgen.1004670

4. Murphy MP. How mitochondria produce reactive oxygen species. Biochem J. 2009;417(1):1-13. https://doi.org/10.1042/bj20081386

5. Hamanaka RB, Chandel NS. Mitochondrial reactive oxygen species regulate cellular signaling and dictate biological outcomes. Trends Biochem Sci. 2010;35(9):505-13. https://doi.org/10.1016/j.tibs.2010.04.002

6. Chernorudskiy AL, Zito E. Regulation of calcium homeostasis by ER redox: a close-up of the ER/mitochondria connection. J Mol Biol. 2017:429(5):620-32. https://doi.org/10.1016/j.jmb.2017.01.017

7. Chen J, Mehta JL, Haider N, Zhang X, Narula J, Li D. Role of caspases in Ox-LDL-induced apoptotic cascade in human coronary artery endothelial cells. Circ Res. 2004:94(3):370-6. https://doi.org/10.1161/01.res.0000113782.07824.be

8. Reubold TF, Eschenburg S. A molecular view on signal transduction by the apoptosome. Cell Signal. 2012;24(7):1420-5. https://doi.org/10.1016/j.cellsig. 2012.03.007

9. Liu CS, Chang JC, Kuo SJ, Liu KH, Lin TT, Cheng WL, Chuang SF. Delivering healthy mitochondria for the therapy of mitochondrial diseases and beyond. Int J Biochem Cell Biol. 2014;53(3):141-6. https://doi.org/10.1016/j. biocel.2014.05.009

10. Cipolat S, Martins de Brito O, Dal Zilio B, Scorrano L. OPA1 requires mitofusin 1 to promote mitochondrial fusion. Proc Natl Acad Sci U S A. 2004;101(45):15927-32. https://doi.org/10.1073/pnas.0407043101

11. McCully JD, Cowan DB, Pacak CA, Toumpoulis IK, Dayalan H, Levitsky S. Injection of isolated mitochondria during early reperfusion for cardioprotection. Am J Phys Heart Circ Phys. 2009;296(1):H94-105. https:// doi.org/10.1152/ajpheart.00567.2008

12. Spees JL, Lee RH, Gregory CA. Mechanisms of mesenchymal stem/stromal cell function. Stem Cell Res Ther. 2016;7(1):125. https://doi.org/10.1186/ s13287-016-0363-7

13. Aghajani Nargesi A, Lerman LO, Eirin A. Mesenchymal stem cell-derived extracellular vesicles for kidney repair: current status and looming challenges. Stem Cell Res Ther. 2017;8(1):273. https://doi.org/10.1186/ s13287-017-0727-7

14. Berebichez-Fridman R, Gomez-Garcia R, Granados-Montiel J, BerebichezFastlicht E, Olivos-Meza A, Granados J, Velasquillo C, Ibarra C. The Holy Grail of orthopedic surgery: mesenchymal stem cells-their current uses and potential applications. Stem Cells Int. 2017;2017(1):2638305. https://doi.org/ 10.1155/2017/2638305

15. Assinck P, Duncan GJ, Hilton BJ, Plemel JR. Cell transplantation therapy for spinal cord injury. Nat Neurosci. 2017;20(5):637-47. https://doi.org/10.1038/nn.4541

16. Wilkerson DC, Sankar U. Mitochondria: a sulfhydryl oxidase and fission GTPase connect mitochondrial dynamics with pluripotency in embryonic stem cells. Int J Biochem Cell Biol. 2011:43(9):1252-6. https://doi.org/10. 1016/j.biocel.2011.05.005
17. Sansone P, Savini C, Kurelac I, Chang Q, Amato LB, Strillacci A, Stepanova A, lommarini L, Mastroleo C, Daly L, Galkin A, Thakur BK, Soplop N, Uryu K, Hoshino A, Norton L, Bonafe M, Cricca M, Gasparre G, Lyden D, Bromberg J. Packaging and transfer of mitochondrial DNA via exosomes regulate escape from dormancy in hormonal therapy-resistant breast cancer. Proc Natl Acad Sci U S A. 2017;114(43):E9066-75. https://doi.org/10.1073/pnas.1704862114

18. Lu J, Zheng X, Li F, Yu Y, Chen Z, Liu Z, Wang Z, Xu H, Yang W. Tunneling nanotubes promote intercellular mitochondria transfer followed by increased invasiveness in bladder cancer cells. Oncotarget. 2017:8(9):15539-52. https://doi.org/10.18632/oncotarget.14695

19. Dong L-F, Kovarova J, Bajzikova M, Bezawork-Geleta A, Svec D, Endaya B, Sachaphibulkij K, Coelho AR, Sebkova N, Ruzickova A, Tan AS, Kluckova K, Judasova K, Zamecnikova K, Rychtarcikova Z, Gopalan V, Andera L, Sobol M, Yan B, Pattnaik B, Bhatraju N, Truksa J, Stopka P, Hozak P, Lam AK, Sedlacek R, Oliveira PJ, Kubista M, Agrawal A, Dvorakova-Hortova K, Rohlena J, Berridge MV, Neuzil J. Horizontal transfer of whole mitochondria restores tumorigenic potential in mitochondrial DNA-deficient cancer cells. elife. 2017;6(1):e22187. https://doi.org/10.7554/eLife.22187

20. Rogers RS, Bhattacharya J. When cells become organelle donors. Physiology (Bethesda, Md). 2013;28(6):414-22. https://doi.org/10.1152/physiol.00032.2013

21. Torralba D, Baixauli F, Sánchez-Madrid F. Mitochondria know no boundaries: mechanisms and functions of intercellular mitochondrial transfer. Front Cell Dev Biol. 2016;4(1):107. https://doi.org/10.3389/fcell.2016.00107

22. Acquistapace A, Bru T, Lesault PF, Figeac F, Coudert AE, le Coz O, Christov C, Baudin X, Auber F, Yiou R, Dubois-Rande $J$, Rodriguez AM. Human mesenchymal stem cells reprogram adult cardiomyocytes toward a progenitor-like state through partial cell fusion and mitochondria transfer. Stem Cells. 2011:29(5):812-24. https://doi.org/10.1002/stem.632

23. Lin HY, Liou CW, Chen SD, Hsu TY, Chuang JH, Wang PW, Huang ST, Tiao MM, Chen JB, Lin TK, Chuang YC. Mitochondrial transfer from Wharton's jelly-derived mesenchymal stem cells to mitochondria-defective cells recaptures impaired mitochondrial function. Mitochondrion. 2015;22(1): 31-44. https://doi.org/10.1016/j.mito.2015.02.006

24. Sinclair KA, Yerkovich ST, Hopkins PM, Chambers DC. Characterization of intercellular communication and mitochondrial donation by mesenchymal stromal cells derived from the human lung. Stem Cell Res Ther. 2016;7(1):91. https://doi.org/10.1186/s13287-016-0354-8

25. Spees JL, Olson SD, Whitney MJ, Prockop DJ. Mitochondrial transfer between cells can rescue aerobic respiration. Proc Natl Acad Sci U S A. 2006;103(5):1283-8. https://doi.org/10.1073/pnas.0510511103

26. Elliott $R L$, Jiang $X P$, Head JF. Mitochondria organelle transplantation: introduction of normal epithelial mitochondria into human cancer cells inhibits proliferation and increases drug sensitivity. Breast Cancer Res Treat. 2012;136(2):347-54. https://doi.org/10.1007/s10549-012-2283-2

27. Vallabhaneni KC, Haller H, Dumler I. Vascular smooth muscle cells initiate proliferation of mesenchymal stem cells by mitochondrial transfer via tunneling nanotubes. Stem Cells Dev. 2012;21(17):3104-13. https://doi.org/ $10.1089 /$ scd.2011.0691

28. Zhang Q, Raoof M, Chen Y, Sumi Y, Sursal T, Junger W, Brohi K, Itagaki K, Hauser CJ. Circulating mitochondrial DAMPs cause inflammatory responses to injury. Nature. 2010:464(7285):104-7. https://doi.org/10.1038/nature08780

29. Weinberg SE, Sena LA, Chandel NS. Mitochondria in the regulation of innate and adaptive immunity. Immunity. 2015:42(3):406-17. https://doi.org/10. 1016/j.immuni.2015.02.002

30. Oka T, Hikoso S, Yamaguchi O, Taneike M, Takeda T, Tamai T, Oyabu J, Murakawa T, Nakayama H, Nishida K, Akira S, Yamamoto A, Komuro I, Otsu K. Mitochondrial DNA that escapes from autophagy causes inflammation and heart failure. Nature. 2012;485(7397):251-5. https://doi.org/10.1038/ nature10992

31. Shimada K, Crother TR, Karlin J, Dagvadorj J, Chiba N, Chen S, Ramanujan VK, Wolf AJ, Vergnes L, Ojcius DM, Rentsendorj A, Vargas M, Guerrero C, Wang Y, Fitzgerald KA, Underhill DM, Town T, Arditi M. Oxidized mitochondrial DNA activates the NLRP3 inflammasome during apoptosis. Immunity. 2012;36(3) 401-14. https://doi.org/10.1016/j.immuni.2012.01.009

32. Collins LV, Hajizadeh S, Holme E, Jonsson IM, Tarkowski A. Endogenously oxidized mitochondrial DNA induces in vivo and in vitro inflammatory responses. J Leukoc Biol. 2004;75(6):995-1000. https://doi.org/10.1189/jlb.0703328

33. Davis C-h O, Kim K-Y, Bushong EA, Mills EA, Boassa D, Shih T, Kinebuchi M, Phan S, Zhou Y, Bihlmeyer NA, Nguyen JV, Jin Y, Ellisman MH, Marsh-Armstrong N. Transcellular degradation of axonal mitochondria. Proc Natl Acad Sci U S A. 2014;111(26):9633-8. https://doi.org/10.1073/pnas.1404651111 
34. Hayakawa K, Esposito E, Wang X, Terasaki Y, Liu Y, Xing C, Ji X, Lo EH. Transfer of mitochondria from astrocytes to neurons after stroke. Nature. 2016;535(7613):551-5. https://doi.org/10.1038/nature18928

35. Yi YC, Chen MJ, Ho JY, Guu HF, Ho ES. Mitochondria transfer can enhance the murine embryo development. J Assist Reprod Genet. 2007;24(10):445-9. https://doi.org/10.1007/s10815-007-9161-6

36. Yamada M, Emmanuele V, Sanchez-Quintero MJ, Sun B, Lallos G, Paull D, Zimmer M, Pagett S, Prosser RW, Sauer MV, Hirano M, Egli D. Genetic drift can compromise mitochondrial replacement by nuclear transfer in human oocytes. Cell Stem Cell. 2016;18(6):749-54. https://doi.org/10.1016/j.stem.2016.04.001

37. Hsu YC, Wu YT, Yu TH, Wei YH. Mitochondria in mesenchymal stem cell biology and cell therapy: from cellular differentiation to mitochondrial transfer. Semin Cell Dev Biol. 2016;52(1):119-31. https://doi.org/10.1016/j.semcdb.2016.02.011

38. Islam MN, Das SR, Emin MT, Wei M, Sun L, Westphalen K, Rowlands DJ, Quadri SK, Bhattacharya S, Bhattacharya J. Mitochondrial transfer from bonemarrow-derived stromal cells to pulmonary alveoli protects against acute lung injury. Nat Med. 2012;18(5):759-65. https://doi.org/10.1038/nm.2736

39. Morrison TJ, Jackson MV, Cunningham EK, Kissenpfennig A, McAuley DF, O'Kane CM, Krasnodembskaya AD. Mesenchymal stromal cells modulate macrophages in clinically relevant lung injury models by extracellular vesicle mitochondrial transfer. Am J Respir Crit Care Med. 2017;196(10):1275-86. https://doi.org/10.1164/rccm.201701-01700C

40. Jackson MV, Morrison TJ, Doherty DF, McAuley DF, Matthay MA, Kissenpfennig A, O'Kane CM, Krasnodembskaya AD. Mitochondrial transfer via tunneling nanotubes is an important mechanism by which mesenchymal stem cells enhance macrophage phagocytosis in the in vitro and in vivo models of ARDS. Stem cells (Dayton, Ohio). 2016;34(8):2210-23. https://doi.org/ $10.1002 /$ stem. 2372

41. Guo R, Davis D, Fang Y. Intercellular transfer of mitochondria rescues virusinduced cell death but facilitates cell-to-cell spreading of porcine reproductive and respiratory syndrome virus. Virology. 2018;517:122-34. https://doi.org/10.1016/j.virol.2017.12.018.

42. Naji A, Suganuma N, Espagnolle N, Yagyu Kl, Baba N, Sensebé L, Deschaseaux F. Rationale for determining the functional potency of mesenchymal stem cells in preventing regulated cell death for therapeutic use. Stem Cells Transl Med. 2017:6(3):713-9. https://doi.org/10.5966/sctm.2016-0289

43. Kong D, Zhu J, Liu Q, Jiang Y, Xu L, Luo N, Zhao Z, Zhai Q, Zhang H, Zhu M, Liu X. Mesenchymal stem cells protect neurons against hypoxic-ischemic injury via inhibiting parthanatos, necroptosis, and apoptosis, but not autophagy. Cell Mol Neurobiol. 2017;37(2):303-13. https://doi.org/10.1007/ s10571-016-0370-3

44. Chen GY, Nuñez G. Sterile inflammation: sensing and reacting to damage. Nat Rev Immunol. 2010;10(12):826-37. https://doi.org/10.1038/nri2873

45. Naji A, Muzembo BA, Yagyu Kl, Baba N, Deschaseaux F, Sensebé L, Suganuma N. Endocytosis of indium-tin-oxide nanoparticles by macrophages provokes pyroptosis requiring NLRP3-ASC-Caspase1 axis that can be prevented by mesenchymal stem cells. Sci Rep. 2016;6(1):26162. https://doi.org/10.1038/ srep26162

46. Cselenyak A, Pankotai E, Horvath EM, Kiss L, Lacza Z. Mesenchymal stem cells rescue cardiomyoblasts from cell death in an in vitro ischemia model via direct cell-to-cell connections. BMC Cell Biol. 2010;11(1):29. https://doi. org/10.1186/1471-2121-11-29

47. Li X, Michaeloudes C, Zhang Y, Wiegman CH, Adcock IM, Lian Q, Mak JCW, Bhavsar PK, Chung KF. Mesenchymal stem cells alleviate oxidative stressinduced mitochondrial dysfunction in the airways. J Allergy Clin Immunol. 2017;(17):31431-8 https://doi.org/10.1016/j.jaci.2017.08.017.

48. Li X, Zhang Y, Yeung SC, Liang Y, Liang X, Ding Y, Ip MS, Tse HF, Mak JC, Lian Q. Mitochondrial transfer of induced pluripotent stem cell-derived mesenchymal stem cells to airway epithelial cells attenuates cigarette smoke-induced damage. Am J Respir Cell Mol Biol. 2014;51(3):455-65. https://doi.org/10.1165/rcmb.2013-05290C

49. Mahrouf-Yorgov M, Augeul L, Da Silva CC, Jourdan M, Rigolet M, Manin S, Ferrera R, Ovize M, Henry A, Guguin A, Meningaud J-P, Dubois-Randé J-L, Motterlini R, Foresti R, Rodriguez A-M. Mesenchymal stem cells sense mitochondria released from damaged cells as danger signals to activate their rescue properties. Cell Death Differ. 2017;24(7):1224-38. https://doi.org/ 10.1038/cdd.2017.51

50. Chen J, Wang Q, Feng X. Umbilical cord-derived mesenchymal stem cells suppress autophagy of $t$ cells in patients with systemic lupus erythematosus via transfer of mitochondria. Stem Cells Int. 2016;2016(1):4062789. https:// doi.org/10.1155/2016/4062789
51. Ahmad T, Mukherjee S, Pattnaik B, Kumar M, Singh S, Kumar M, Rehman R, Tiwari BK, Jha KA, Barhanpurkar AP, Wani MR, Roy SS, Mabalirajan U, Ghosh B, Agrawal A. Miro1 regulates intercellular mitochondrial transport \& enhances mesenchymal stem cell rescue efficacy. EMBO J. 2014;33(9): 994-1010. https://doi.org/10.1002/embj.201386030

52. Chang KT, Niescier RF, Min KT. Mitochondrial matrix Ca2+ as an intrinsic signal regulating mitochondrial motility in axons. Proc Natl Acad Sci U S A. 2011;108(37):15456-61. https://doi.org/10.1073/pnas.1106862108

53. Macaskill AF, Rinholm JE, Twelvetrees AE, Arancibia-Carcamo IL, Muir J, Fransson A, Aspenstrom P, Attwell D, Kittler JT. Miro1 is a calcium sensor for glutamate receptor-dependent localization of mitochondria at synapses. Neuron. 2009;61(4):541-55. https://doi.org/10.1016/j.neuron.2009.01.030

54. Saotome M, Safiulina D, Szabadkai G, Das S, Fransson A, Aspenstrom P, Rizzuto R, Hajnoczky G. Bidirectional Ca2+-dependent control of mitochondrial dynamics by the Miro GTPase. Proc Natl Acad Sci U S A. 2008;105(52):20728-33. https://doi.org/10.1073/pnas.0808953105

55. Wang X, Schwarz TL. The mechanism of Ca2+-dependent regulation of kinesin-mediated mitochondrial motility. Cell. 2009;136(1):163-74. https:// doi.org/10.1016/j.cell.2008.11.046

56. Chada SR, Hollenbeck PJ. Nerve growth factor signaling regulates motility and docking of axonal mitochondria. Curr Biol. 2004;14(14):1272-6. https:// doi.org/10.1016/j.cub.2004.07.027

57. Yu JW, Lee MS. Mitochondria and the NLRP3 inflammasome: physiological and pathological relevance. Arch Pharm Res. 2016;39(11):1503-18. https:// doi.org/10.1007/s12272-016-0827-4

58. Stamer K, Vogel R, Thies E, Mandelkow E, Mandelkow EM. Tau blocks traffic of organelles, neurofilaments, and APP vesicles in neurons and enhances oxidative stress. J Cell Biol. 2002;156(6):1051-63. https://doi.org/10.1083/jcb.200108057

59. Dubey M, Chaudhury P, Kabiru H, Shea TB. Tau inhibits anterograde axonal transport and perturbs stability in growing axonal neurites in part by displacing kinesin cargo: neurofilaments attenuate tau-mediated neurite instability. Cell Motil Cytoskeleton. 2008;65(2):89-99. https://doi.org/10.1002/cm.20243

60. Stoothoff W, Jones PB, Spires-Jones TL, Joyner D, Chhabra E, Bercury K, Fan Z, Xie H, Bacskai B, Edd J, Irimia D, Hyman BT. Differential effect of threerepeat and four-repeat tau on mitochondrial axonal transport. J Neurochem. 2009;111(2):417-27. https://doi.org/10.1111/j.1471-4159.2009.06316.x

61. Mandelkow EM, Thies E, Trinczek B, Biernat J, Mandelkow E. MARK/PAR1 kinase is a regulator of microtubule-dependent transport in axons. J Cell Biol. 2004;167(1):99-110. https://doi.org/10.1083/jcb.200401085

62. Rustom A, Saffrich R, Markovic I, Walther P, Gerdes HH. Nanotubular highways for intercellular organelle transport. Science (New York, NY). 2004; 303(5660):1007-10. https://doi.org/10.1126/science.1093133

63. Bukoreshtliev NV, Wang X, Hodneland E, Gurke S, Barroso JF, Gerdes HH. Selective block of tunneling nanotube (TNT) formation inhibits intercellular organelle transfer between PC12 cells. FEBS Lett. 2009;583(9):1481-8. https:// doi.org/10.1016/j.febslet.2009.03.065

64. Onfelt B, Nedvetzki S, Yanagi K, Davis DM. Cutting edge: Membrane nanotubes connect immune cells. J Immunol. 2004;173(3):1511-3.

65. Hase K, Kimura S, Takatsu H, Ohmae M, Kawano S, Kitamura H, Ito M, Watarai H, Hazelett CC, Yeaman C, Ohno H. M-Sec promotes membrane nanotube formation by interacting with Ral and the exocyst complex. Nat Cell Biol. 2009;11(12):1427-32. https://doi.org/10.1038/ncb1990

66. Liu K, Ji K, Guo L, Wu W, Lu H, Shan P, Yan C. Mesenchymal stem cells rescue injured endothelial cells in an in vitro ischemia-reperfusion model via tunneling nanotube like structure-mediated mitochondrial transfer. Microvasc Res. 2014;92:10-8. https://doi.org/10.1016/j.mvr.2014.01.008

67. Yang H, Borg TK, Ma Z, Xu M, Wetzel G, Saraf LV, Markwald R, Runyan RB, Gao BZ. Biochip-based study of unidirectional mitochondrial transfer from stem cells to myocytes via tunneling nanotubes. Biofabrication. 2016;8(1): 015012. https://doi.org/10.1088/1758-5090/8/1/015012

68. Jiang D, Gao F, Zhang Y, Wong DS, Li Q, Tse HF, Xu G, Yu Z, Lian Q. Mitochondrial transfer of mesenchymal stem cells effectively protects corneal epithelial cells from mitochondrial damage. Cell Death Dis. 2016; 7(11):e2467. https://doi.org/10.1038/cddis.2016.358

69. Pekkurnaz G, Trinidad JC, Wang X, Kong D, Schwarz TL. Glucose regulates mitochondrial motility via Milton modification by O-GICNAc transferase. Cell. 2014;158(1):54-68. https://doi.org/10.1016/j.cell.2014.06.007

70. Thayanithy V, Dickson EL, Steer C, Subramanian S, Lou E. Tumor-stromal cross talk: direct cell-to-cell transfer of oncogenic microRNAs via tunneling nanotubes. Trans| Res. 2014;164(5):359-65. https://doi.org/10. 1016/j.trsl.2014.05.011 
71. Lou E, Fujisawa S, Morozov A, Barlas A, Romin Y, Dogan Y, Gholami S, Moreira AL, Manova-Todorova K, Moore MA. Tunneling nanotubes provide a unique conduit for intercellular transfer of cellular contents in human malignant pleural mesothelioma. PLoS One. 2012;7(3):e33093. https://doi. org/10.1371/journal.pone.0033093

72. Moschoi R, Imbert V, Nebout M, Chiche J, Mary D, Prebet T, Saland E, Castellano R, Pouyet L, Collette Y, Vey N, Chabannon C, Recher C, Sarry JE, Alcor D, Peyron JF, Griessinger E. Protective mitochondrial transfer from bone marrow stromal cells to acute myeloid leukemic cells during chemotherapy. Blood. 2016;128(2):253-64. https://doi.org/10.1182/blood2015-07-655860

73. Wang Y, Cui J, Sun X, Zhang Y. Tunneling-nanotube development in astrocytes depends on p53 activation. Cell Death Differ. 2011;18(4):732-42. https://doi.org/10.1038/cdd.2010.147

74. Eugenin EA, Gaskill PJ, Berman JW. Tunneling nanotubes (TNT): a potential mechanism for intercellular HIV trafficking. Commun Integ Biol. 2009;2(3):243-4.

75. Domhan S, Ma L, Tai A, Anaya Z, Beheshti A, Zeier M, Hlatky L, Abdollahi A. Intercellular communication by exchange of cytoplasmic material via tunneling nano-tube like structures in primary human renal epithelial cells. PLoS One. 2011;6(6):e21283. https://doi.org/10.1371/journal.pone.0021283

76. Phinney DG, Di Giuseppe M, Njah J, Sala E, Shiva S, St Croix CM, Stolz DB, Watkins SC, Di YP, Leikauf GD, Kolls J, Riches DWH, Deiuliis G, Kaminski N, Boregowda SV, McKenna DH, Ortiz LA. Mesenchymal stem cells use extracellular vesicles to outsource mitophagy and shuttle microRNAs. Nat Commun. 2015;6(1):8472. https://doi.org/10.1038/ncomms9472

77. Otsu K, Das S, Houser SD, Quadri SK, Bhattacharya S, Bhattacharya J. Concentration-dependent inhibition of angiogenesis by mesenchymal stem cells. Blood. 2009;113(18):4197-205. https://doi.org/10.1182/blood2008-09-176198

78. Kitani T, Kami D, Matoba S, Gojo S. Internalization of isolated functional mitochondria: involvement of macropinocytosis. J Cell Mol Med. 2014;18(8): 1694-703. https://doi.org/10.1111/jcmm.12316

79. Kesner EE, Saada-Reich A, Lorberboum-Galski H. Characteristics of mitochondrial transformation into human cells. Sci Rep. 2016;6(1):26057. https://doi.org/10.1038/srep26057

80. Pacak CA, Preble JM, Kondo H, Seibel P, Levitsky S, del Nido PJ, Cowan DB, McCully JD. Actin-dependent mitochondrial internalization in cardiomyocytes: evidence for rescue of mitochondrial function. Biol Open. 2015;4(5):622-6. https://doi.org/10.1242/bio.201511478

81. Borbolla JR, Lopez-Hernandez MA, De Diego J, Gonzalez-Avante M, Trueba E, Collados MT. Use of interleukin-11 after autologous stem cell transplant: report of three cases and a very brief review of the literature. Haematologica. 2001;86(8):891-2.

82. Lozano-Elena F, Planas-Riverola A, Vilarrasa-Blasi J, Schwab R, Cano-Delgado Al. Paracrine brassinosteroid signaling at the stem cell niche controls cellular regeneration. J Cell Sci. 2018;131(2). https://doi.org/10.1242/jcs.204065.

83. Caicedo A, Fritz V, Brondello JM, Ayala M, Dennemont I, Abdellaoui N, de Fraipont F, Moisan A, Prouteau CA, Boukhaddaoui H, Jorgensen C, Vignais ML. MitoCeption as a new tool to assess the effects of mesenchymal stem/ stromal cell mitochondria on cancer cell metabolism and function. Sci Rep. 2015;5(1):9073. https://doi.org/10.1038/srep09073

84. Gollihue JL, Patel SP, Mashburn C, Eldahan KC, Sullivan PG, Rabchevsky AG. Optimization of mitochondrial isolation techniques for intraspinal transplantation procedures. J Neurosci Methods. 2017;287(1):1-12. https:// doi.org/10.1016/j.jneumeth.2017.05.023

85. Zhang Y, Yu Z, Jiang D, Liang X, Liao S, Zhang Z, Yue W, Li X, Chiu SM, Chai YH, Liang Y, Chow Y, Han S, Xu A, Tse HF, Lian Q. iPSC-MSCs with high intrinsic MIRO1 and sensitivity to TNF-alpha yield efficacious mitochondrial transfer to rescue anthracycline-induced cardiomyopathy. Stem Cell Reports. 2016;7(4):749-63. https://doi.org/10.1016/j.stemcr.2016.08.009

86. Babenko VA, Silachev DN, Zorova LD, Pevzner IB, Khutornenko AA, Plotnikov EY, Sukhikh GT, Zorov DB. Improving the post-stroke therapeutic potency of mesenchymal multipotent stromal cells by cocultivation with cortical neurons: the role of crosstalk between cells. Stem Cells Transl Med. 2015; 4(9):1011-20. https://doi.org/10.5966/sctm.2015-0010

87. Han H, Hu J, Yan Q, Zhu J, Zhu Z, Chen Y, Sun J, Zhang R. Bone marrowderived mesenchymal stem cells rescue injured H9c2 cells via transferring intact mitochondria through tunneling nanotubes in an in vitro simulated ischemia/reperfusion model. Mol Med Rep. 2016;13(2):1517-24. https://doi. org/10.3892/mmr.2015.4726
88. Hu J, Deng G, Tian Y, Pu Y, Cao P, Yuan W. An in vitro investigation into the role of bone marrowderived mesenchymal stem cells in the control of disc degeneration. Mol Med Rep. 2015;12(4):5701-8. https://doi.org/10.3892/ mmr.2015.4139

89. Yasuda K, Park HC, Ratliff B, Addabbo F, Hatzopoulos AK, Chander P, Goligorsky MS. Adriamycin nephropathy: a failure of endothelial progenitor cell-induced repair. Am J Pathol. 2010;176(4):1685-95. https://doi.org/10.2353/ajpath. 2010.091071 